\title{
Kecerdasan Emosi Siswa Ditinjau dari Jenis Kelamin dan Jenjang Kelas
}

\author{
Khairul Bariyyah ${ }^{1^{*}}$ \& Leny Latifah ${ }^{2}$ \\ ${ }^{12}$ Universitas Kanjuruhan Malang \\ *Corresponding author, e-mail: khairulbariyyah@unikama.ac.id
}

\begin{abstract}
Abtract
Emotional intelligence refers to the capability of a person to manage and control his or her emotions and possess the ability to control the emotions of others as well. Emotional intelligence is a very important skill for students. It is said to have five main elements such as self-awareness, self-regulation, motivation, empathy, and social skills. The purpose of this study First, to describe the level of emotional intelligence of junior high school students of Malang. Second, describe the differences of emotional intelligence based on gender and grade level. This research method is quantitative descriptive. The research sample was 313 students of State Junior High Schools in Malang selected by cluster random sampling technique. The research instrument used a scale of emotional intelligence consisting of 48 items, data analysis using descriptive analysis and T-test. The results showed 1) 25.9\% students of State Junior High Schools in Malang were at a high level of emotional intelligence, $61.3 \%$ students of State Junior High Schools in Malang were at the level moderate emotional intelligence, $12.8 \%$ of students are at a low level of emotional intelligence. (2) there is a significant difference between the level of emotional intelligence of students based on gender, (3) there is a significant difference in the level of emotional intelligence of students from the grade level.
\end{abstract}

Keywords: Emotional intelligence, Students of State Junior High Schools, Gender, Grade Level

This is an open access article distributed under the Creative Commons Attribution License, which permits unrestricted use,
distribution, and reproduction in any medium, provided the original work is properly cited. $\odot 2019$ by author

\section{PENDAHULUAN}

Perkembangan teknologi terutama dalam bidang informasi dan komunikasi telah memberikan pengaruh yang cukup signifikan bagi dunia pendidikan. Salah satunya bagaimana dunia pendidikan mampu menghadapi berbagai tantangan mulai dari tantangan global, nasional, dan lokal (Yuniarto, 2016). Salah satu tantangan yang harus dihadapi adalah membentuk karakter anak bangsa. Dalam Undang-undang Nomor 20 Tahun 2003 tentang Sistem Pendidikan Nasional disebutkan bahwa pendidikan nasional berfungsi mengembangkan kemampuan dan membentuk watak serta peradaban bangsa yang bermartabat dalam rangka mencerdaskan kehidupan bangsa, bertujuan untuk berkembangnya potensi peserta didik agar menjadi manusia yang beriman dan bertakwa kepada Tuhan Yang Maha Esa, berakhlak mulia, sehat, berilmu, cakap, kreatif, mandiri, dan menjadi warga Negara yang demokrasi serta bertanggung jawab.

Selain bertujuan untuk meningkatkan kecerdasan intelektual, Pendidikan juga perlu membina karakter peserta didik salah satunya bagaimana peserta didik memiliki kecerdasan emosi (Hendri, 2010). Tujuan pendidikan nasional jelas telah meletakkan dasar-dasar yang kuat dalam menopang pembangunan karakter dan jati diri bangsa. stabil sebagai penyeimbang dari inteligensi yang ada. Kecerdasan emosi dapat membentuk karakter peserta didik secara positif, mampu memahami diri dan lingkungannya secara tepat, memiliki rasapercaya diri, tidak mudah putus asa (Al Kahtani, 2013). Berbagai hasil kajian dan pengalaman menunjukkan, bahwa pembelajaran komponen emosional lebih penting daripada intelektual (Matthews \& Folsom, 2013; Zhang, 2015; Batool, 2013). 
Kecerdasan Emosi adalah istilah yang dipopulerkan Daniel Goleman. Menurut Goleman (2001) kecerdasan emosi adalah kemampuan seseorang mengatur kehidupan emosinya dengan intelegensi (to ménage our emotional life with intellegenece), menjaga keselarasan emosi dan pengungkapannya (the appropriatenessof emotion and its expression) melalui keterampilan kesadaran diri, pengendalian diri, motivasi diri, empati diri dan keterampilan sosial. Dengan kata lain kecerdasan emosi adalah kemampuan seseorang untuk memahami dan mengenali emosi diri, mengelola emosi diri, memotivasi diri sendiri, mengenali emosi orang lain (empati) dan kemampuan untuk membina hubungan (kerjasama) baik dengan orang lain.

Fitriastuti (2013) mendefinisikan bahwa kecerdasan emosi sebagai suatu kecerdasan sosial yang berkaitan dengan kemampuan individu dalam memantau baik emosi dirinya maupun emosi orang lain, dan juga kemampuannya dalam membedakan emosi dirinya dengan emosi orang lain, dimana kemampuan ini digunakan untuk mengarahkan pola pikir dan perilakunya.Kecerdasan Emosi (EQ) berfokus bagaimana mampu membangun hubungan harmonis, serasi dan selaras antarmanusia secara horizontal, sehingga kecerdasan intelegensi (IQ) yang dimilikinya pasti bermanfaat (Al Ahyadi, 2015). Kecerdasan emosional dapat ditunjukkan melalui kemampuan seseorang untuk menyadari apa yang dia dan orang lain rasakan. Oleh karena itu, peserta didik yang memiliki tingkat kecerdasan emosional yang lebih baik, cenderung dapat menjadi lebih terampil dalam menenangkan dirinya dengan cepat, lebih terampil dalam memusatkan perhatian, lebih baik dalam berhubungan dengan orang lain, lebih cakap dalam memahami orang lain, dan untuk kerja akademis di sekolah lebih baik.

Kecerdasan emosi juga menunjang kesuksesan seseorang. Menurut Goleman (2001) kontribusi IQ jika di prosentasekan dalam menunjang kesuksesan tak lebih dari $20 \%$ dan sisanya $80 \%$ didukung oleh factor-faktor lainnya, termasuk kecerdasan emosi (EQ). Dari hasil prosentase yang sudah dibuktikan oleh Goleman (2001) menunjukkan bahwa bahwa dalam dunia pendidikan, penilaian untuk mengkur baik buruknya siswa tidak hanya dengan melihat seberapa besar IQ yang dimiliki siswa namun juga melihat seberapa besar EQ yang dimiliki siswa tersebut untuk menjadikan siswa tersebut menjadi siswa yang diharapkan.Dalam belajar siswa, kedua inteligensi itu sangat diperlukan. IQ tidak dapat berfungsi dengan baik tanpa partisipasi penghayatan emosional terhadap mata pelajaran yang disampaikan di sekolah (Gusniwati, 2015; Uljarevic \& Hamilton, 2013). Namun biasanya kedua inteligensi itu saling melengkapi. Keseimbangan antara IQ dan EQ merupakan kunci keberhasilan belajar siswa di sekolah (Goleman, 2001; Setyawan, Budiyono, \& Slamet, 2017). Pendidikan di sekolah bukan hanya perlu mengembangkan rational intelligence yaitu model pemahaman yang lazimnya dipahami siswa saja, melainkan juga perlu mengembangkan emotional intelligence siswa

Beberapa hasil penelitian selain menunjukkan bahwa kecerdasan emosional selain menunjang kesuksesan siswa, juga berpengaruh terhadap hasil belajar siswa (Setyawan \& Simbolon, 2018), berkorelasi positif dengan dengan interaksi sosial siswa (Putri, Asrori \& Astuti, 2015) dan dan memiliki dampak positif terhadap meningkatnya kecerdasan spiritual dan perilaku prososial remaja (Yantiek, 2014). Dari hasil-hasil penelitian ini dapat disimpulkan bahwa aspek kecerdasan emosi perlu untuk diperhatikan oleh pihak sekolah untuk para siswanya karena kecerdasan emosi sangat berpengaruh terhadap perilaku siswa.

Peristiwa yang telah terjadi di Indonesia belakangan ini menunjukkan rendahnya kecerdasan emosi siswa seperti kasus siswa yang membawa sabit ke sekolah karena ponselnya disita oleh guru (Kompas.Com,5 Oktober 2019), Melanggar dan ditilang polisi, siswa marah-marah (Tribunbatam.id, 17 Agustus 2019), Seorang siswa di Batam menghajar semua teman-temannnya yang melakukan Bullyan( Tribunbatam.id, 22 November 2019), Gara-gara Ledekan, Siswa SMP di Pekanbaru Dianiaya di Kelas (Detik.news, 09 November 2019). Beberapa kejadian-kejadian ini harus segera mendapatkan solusi agar para siswa mendapatkan pembinaan terutama tentang pembinaan kecerdasan emosinya mengingat mereka masih dalam masa remaja.

Masa remaja juga disebutkan sebagai masa badai dan stress (storm and stress) yaitu suatu masa di mana ketegangan emosi meninggi sebagai akibat dari perubahan fisik dan kelenjar. Meningginya emosi disebabkan karena remaja berada dalam sebuah tekanan yang menuntutnya untuk menjadi harapan baru yang baik di masa depan. Oleh karena itu dalam memberikan layanan bantuan kepada siswa, khususnya siswa yang mengalami kesulitan dalam menyeimbangkan kecerdasan emosional, konselor memerlukan berbagai data tentang kecerdasan emosi melalui pengumpulan data. Penelitian ini dilakukan merupakan langkah awal untuk mendeskripsi tingkat kecerdasan emosi siswa sehingga dapat menjadi data awal untuk menentukan langkah lanjut bagi peningkatan kecerdasan emosi siswa.

Tujuan penelitian ini Pertama, untuk mengetahui dan mendeskripsikan tingkat kecerdasan emosi siswa SMP di kota Malang. Kedua, mendeskripsikan perbedaan tingkat kecerdasan emosi berdasarkan jenis kelamin dan jenjang kelas. 


\section{METODE}

Penelitian ini merupakan tinjauan awal yang berbentuk deskriptif kuantittaif. Penelitian ini melibatkan 313 siswa SMP Negeri di Kota Malang yang dipilih dengan teknik cluster random sampling. Instrument penelitian menggunakan skala kecerdasan emosi yang terdiri dari 48 item, dikembangkan oleh peneliti berdasarkan teori Goleman (2001) dan memiliki tingkat validitas dan reliabilitas yang tinggi yaitu 0,906. Untuk menjawab pertanyaan penelitian tentang tingkat kecerdasan emosi siswa, data diolah dengan menggunkana statistic kurva normal, dengan menentukan Mean (rata-rata) dihitung prosentase yang ada dalam ketegori tinggi, sedang dan rendah. Sedangkan untuk membuktikan hipotes penelitian tentang perbedaan tingkat kesadaran multicultural siswa berdasarkan jenis kelamin dan kelas, data diolah dengan mengunakan rumus Uji T

\section{HASIL PENELITIAN}

\section{Tingkat Kecerdasan Emosi Siswa SMPN}

Variabel Kecerdasan Emosi dijawab oleh 313 responden. Berdasarkan hasil analisis data skala Kecerdasan Emosi yang terdiri dari 48 item pernyataan diperoleh hasil sebagaimana yang dijabarkan dalam table 1 berikut:

Tabel 1. Tingkat kecerdasan emosi siswa

\begin{tabular}{|c|c|c|}
\hline Kategori & Frekuensi & Prosentase \\
\hline Rendah & 40 & $12,8 \%$ \\
\hline Sedang & 192 & $61,3 \%$ \\
\hline Tinggi & 81 & $25,9 \%$ \\
\hline Total & 313 & $100,0 \%$ \\
\hline
\end{tabular}

Dari tabel table 1 tersebut dapat digambarkan bahwa 25,9\% Siswa SMPN berada pada tingkat Kecerdasan Emosi tinggi, 61,3\% Siswa SMPN berada pada tingkat Kecerdasan Emosi sedang, 12,8\% Siswa SMPN berada pada tingkat Kecerdasan Emosi rendah. Dapat disimpulkan bahwa prosentase paling banyak adalah Siswa SMPN yang berada dalam kategori tingkat Kecerdasan Emosi sedang $(61,3 \%)$. Lebih jelasnya dapat dilihat pada tabel grafik berikut ini:

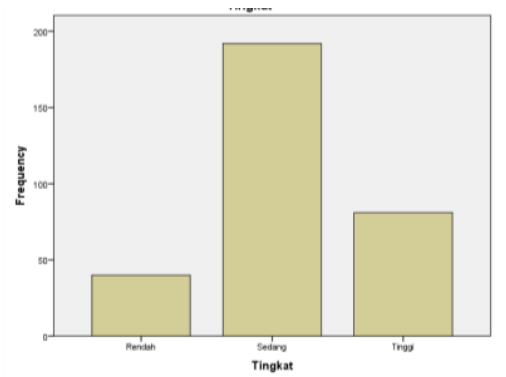

Gambar 1. Tingkat kecerdasan emosi siswa

\section{Tingkat Kecerdasan Emosi Berdasarkan Jenis Kelamin}

Deskripsi tingkat Kecerdasan Emosi Siswa SMPN berdasarkan jenis kelamin

Skala Kecerdasan Emosi dijawab oleh 151 Siswa SMPN berjenis kelamin laki-laki dan 162 berjenis kelamin perempuan. Berdasarkan hasil analisis data skala Kecerdasan Emosi yang terdiri dari 48 item didapat hasil sebagaimana yang dijabarkan dalam tabel 2

Tabel 2. Tingkat kecerdasan emosi siswa laki-laki

\begin{tabular}{lccc}
\hline & Kategori & Frekuensi & Prosentase \\
\hline Rendah & 30 & $19,9 \%$ \\
Sedang & 92 & $60,9 \%$ \\
Tinggi & 29 & $19,2 \%$ \\
\hline Total & 151 & $100,0 \%$ \\
\hline
\end{tabular}

Dari tabel 2 tersebut dapat digambarkan dari 151 Siswa SMPN berjenis kelamin laki-laki terdapat 19,2\% Siswa berada pada tingkat Kecerdasan Emosi tinggi, 60,9\% Siswa berada pada tingkat Kecerdasan Emosi sedang, 19.9 \% Siswa berada pada tingkat kecerdasan emosi rendah. Dapat disimpulkan bahwa Siswa SMPN 
berjenis kelamin laki-laki yang mempunyai prosentase paling banyak adalah siswa yang berada dalam kategori tingkat kecerdasan emosi sedang $(60,9 \%)$.

Tabel 3. Tingkat kecerdasan emosi siswi perempuan

\begin{tabular}{|c|c|c|}
\hline Kategori & Frekuensi & Prosentase \\
\hline Rendah & 10 & $6,2 \%$ \\
\hline Sedang & 100 & $61,7 \%$ \\
\hline Tinggi & 52 & $32,1 \%$ \\
\hline Total & 162 & $100,0 \%$ \\
\hline
\end{tabular}

Dari tabel 3 tersebut dapat digambarkan bahwa 32,1\% Siswa berjenis kelanin perempuan berada pada tingkat Kecerdasan Emosi tinggi, 61,7\% Siswa berada pada tingkat Kecerdasan Emosi sedang, 6,2\% Siswa berada pada tingkat kecerdasan emosi rendah. dapat disimpulkan bahwa siswa berjenis kelanin perempuan yang mempunyai prosentase paling banyak adalah siswa yang berada dalam kategori tingkat kecerdasan emosi sedang $(61,7 \%)$.

\section{Perbedaan tingkat Kecerdasan Emosi Siswa SMPN berdasarkan jenis kelamin}

Tabel 4 menunjukkan bahwa nilai $\mathrm{F}$ untuk jenis kelamin dengan equal variance assumed adalah 5,216 dengan signifikansi 0,023. Karena probabilitas < 0,05 sehingga menunjukkan bahwa kedua varians dari populasi adalah tidak identik. Oleh karena itu, nilai t-test yang akan dipakai berdasar kepada nilai equal variances not assumed.

Tabel 4. Hasil uji coba Independent Samples Test

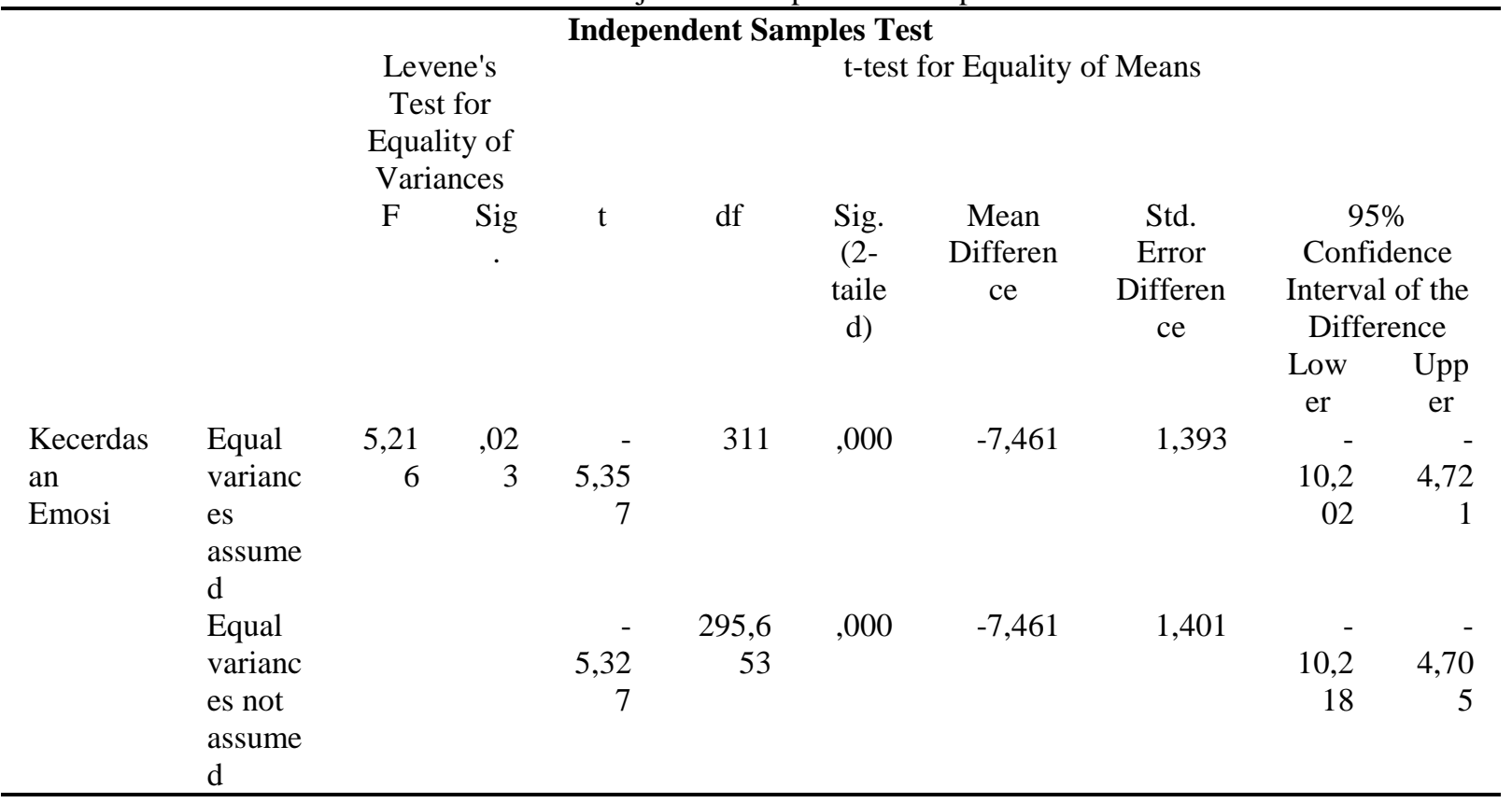

Berdasarkan nilai t-test yang diperoleh terlihat bahwa t hitung adalah -5,327 dengan signifikansi 0,000. Oleh karena signifikansi $0,000<0,05$ maka diperoleh kesimpulan bahwa terdapat perbedaan yang signifikan antara tingkat kecerdasan emosi siswa laki-laki dan perempuan, dengan kata lain terdapat perbedaan yang signifikan tingkat kecerdasan emosi siswa dari jenis kelamin

\section{Tingkat Kecerdasan Emosi Siswa Berdasarkan Kelas}

\section{Deskripsi tingkat Kecerdasan Emosi Siswa SMPN berdasarkan kelas}

Skala Kecerdasan Emosi dijawab oleh 133 Siswa SMPN kelas 7 dan 180 Siswa SMPN kelas 8. Berdasarkan hasil analisis data skala Kecerdasan Emosi yang terdiri dari 48 item didapat hasil sebagaimana yang dijabarkan dalam tabel 5. Dalam tabel 5 tersebut dapat digambarkan dari 133 Siswa SMPN kelas 7 terdapat 24,8 \% Siswa berada pada tingkat Kecerdasan Emosi tinggi, 57,9 \%Siswa berada pada tingkat Kecerdasan Emosi sedang, 17,3 $\%$ Siswa berada pada tingkat Kecerdasan Emosi rendah. Dapat disimpulkan bahwa Siswa SMPN kelas 7 yang 
mempunyai prosentase paling banyak adalah siswa yang berada dalam kategori tingkat Kecerdasan Emosi sedang $(57,9 \%)$.

Tabel 5. Tingkat kecerdasan emosi siswa kelas 7

\begin{tabular}{|c|c|c|}
\hline Kategori & Frekuensi & Prosentase \\
\hline Rendah & 23 & $17,3 \%$ \\
\hline Sedang & 77 & $57,9 \%$ \\
\hline Tinggi & 33 & $24,8 \%$ \\
\hline Total & 133 & $100,0 \%$ \\
\hline
\end{tabular}

Lebih lanjut dalam table 5a digambarkan dari 180 Siswa SMPN kelas 8 terdapat 26,7 \% Siswa berada pada tingkat Kecerdasan Emosi tinggi, 63,9 \% Siswa berada pada tingkat Kecerdasan Emosi sedang, 9,4 \%Siswa berada pada tingkat Kecerdasan Emosi rendah. Dapat disimpulkan bahwa Siswa SMPN kelas 8 yang mempunyai prosentase paling banyak adalah siswa yang berada dalam kategori tingkat Kecerdasan Emosi sedang $(63,9 \%)$

Tabel 6. Tingkat kecerdasan emosi siswa kelas 7

\begin{tabular}{|c|c|c|}
\hline Kategori & Frekuensi & Prosentase \\
\hline Rendah & 17 & $9,4 \%$ \\
\hline Sedang & 115 & $63,9 \%$ \\
\hline Tinggi & 48 & $26,7 \%$ \\
\hline Total & 180 & $100,0 \%$ \\
\hline
\end{tabular}

\section{Perbedaan tingkat Kecerdasan Emosi Siswa SMPN berdasarkan kelas}

Tabel 6. menunjukkan bahwa nilai $\mathrm{F}$ untuk kelas dengan equal variance assumed adalah 0,056 dengan signifikansi 0,813. Karena probabilitas > 0,05 sehingga menunjukkan bahwa kedua varians dari populasi adalah identik. Oleh karena itu, nilai t-test yang akan dipakai berdasar kepada nilai equal variances assumed.

Tabel 6. Independent Samples Test Kecerdasan Emosi berdasarkan kelas

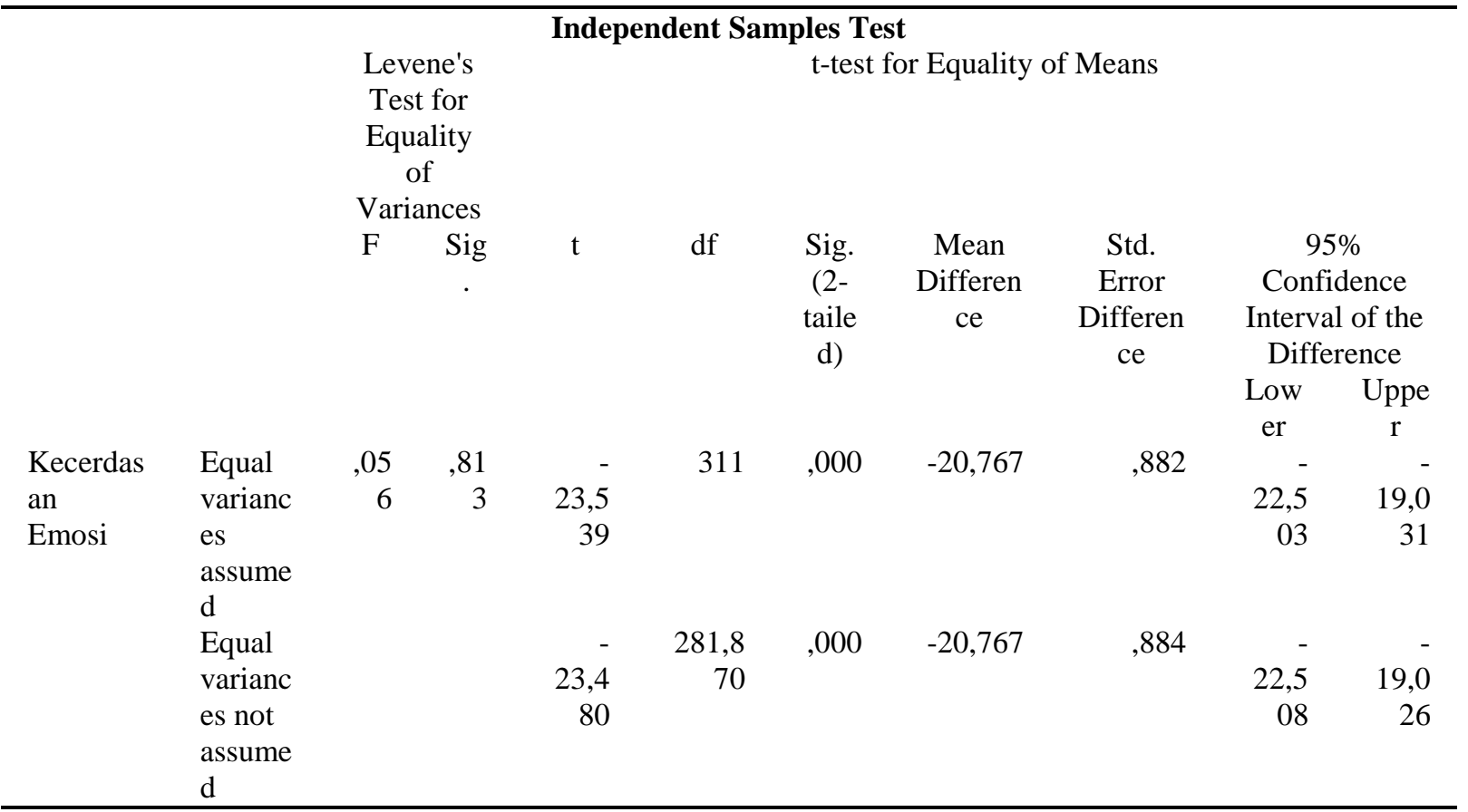

Berdasarkan nilai t-test yang diperoleh terlihat bahwa t hitung adalah -23,539 dengan signifikansi 0,000. Oleh karena signifikansi $0,000<0,05$ maka diperoleh kesimpulan bahwa terdapat perbedaan yang signifikan antara tingkat Kecerdasan Emosi Siswa kelas 7 dan kelas 8, dengan kata lain terdapat perbedaan yang signifikan tingkat Kecerdasan Emosi Siswa dari jenjang kelas. 


\section{PEMBAHASAN}

Berdasarkan hasil penelitian dapat disimpulkan bahwa tingkat kecerdasan emosi siswa SMP Negeri di Kota Malang berada pada kategori sedang $(61,3 \%)$. Hal ini berarti siswa sudah mampu mengenali dan mengelola emosi diri sendiri, mampu memotivasi diri sendiri, mengenal emosi orang lain (empati), dan cakap dalam membina hubungan baik dengan orang lain. Meskipun telah berada dalam kategori sedang, namun siswa masih perlu mendapatkan pembinaan bagaimana meningkatkan kecerdasan emosinya hingga menjadi kategori tinggi. Batubara (2016) menyatakan bahwa siswa SMP yang masih berada pada masa remaja kepribadiannya banyak dipengaruhi oleh lingkungan dan teman-teman sebayanya. Agar dapat terhindar dari hal-hal negatif yang dapat merugikan dirinya sendiri dan orang lain, remaja hendaknya memahami pentingnya kecerdasan emosi. Kecerdasan ini terlihat dalam beberapa hal seperti bagaimana remaja mampu memberi kesan yang baik tentang dirinya, mampu mengungkapkan dengan baik emosinya sendiri, dapat mengendalikan perasaan serta mampu mengungkapkan reaksi emosi sesuai kondisi yang ada sehingga interaksi dengan orang lain mampu terjalin baik dan efektif.

Fitri \& Adelya (2017) menyatakan bahwa remaja yang dapat melatih emosinya, akan lebih mampu menguasai emosi-emosi yang negatif, dan dapat membantu untuk menghadapi berbagai situasi yang akan mendatangkan kebahagiaan bagi mereka. Remaja yang memiliki kecerdasan emosi akan lebih terampil dalam menenangkan dirinya. Menurut Batubara (2016) remaja yang belajar mengenali dan menguasai emosinya akan menjadi lebih percaya diri, lebih sehat secara fisik dan psikis, dan cenderung akan menjadi orang yang sehat secara emosi.Hasil temuan ke 2 dalam penelitian ini yaitu terdapat perbedaan yang signifikan tingkat kecerdasan emosi siswa berdasarkan jenis kelamin. Meskipun rata-rata kecerdasan emosi siswa laki-laki dan perempuan sama berada dalam kategori sedang, tetapi prosentase kecerdasan emosi siswa perempuan yang berada di kategori sedang lebih tinggi dibandingkan prosentase kecerdasan emosi siswa laki-laki. Selain itu kecerdasan emosi siswa perempuan yang berada di kategori tinggi juga lebih banyak yaitu $32,1 \%$.

Goleman (2001) menyatakan ada beberapa faktor yang mempengaruhi kecerdasan emosional, yaitu: pengalaman, usia, jenis kelamin dan jabatan. Berdasarkan hasil peneltian ini dapat dipahami jika perempuan memiliki kecerdasan emosi yang lebih tinggi dibandingkan laki-laki. Perempuan cenderung memiliki sifat keibuan, empati, dan lebih menggunakan perasaan dalam bertindak sehingga kecerdasan emosinya lebih tinggi (Chong, Mahamod \& Yamat, 2016).. Selain itu siswa perempuan lebih sensitif terhadap lingkungan sekitarnya, mengenali dan mampu mengelola emosi dibandingkan laki-laki (Meyers-Levy, \& Loken, 2015). Jika kita lihat di lingkungan sekitar kita, persahaban anak-anak perempuan juga lebih intim dan lebih saling memahami dibandingkan persahabatan anak laki-laki (Chow, Ruhl \& Buhrmester, 2013). Hal inilah yang mendasari mengapa kecerdasan emosi siswa perempuan juga lebih tinggi dibandingkan kecerdasan emosi siswa laki-laki.

Hasil penelitian ini juga mendukung hasil penelitian Jati \& Yoenanto (2013) yang menunjukkan adanya perbedaan signifikan kecerdasan emosional siswa ditinjau dari jenis kelamin. Lebih lanjut hasil penelitian Hasanuddin (2018) juga menunjukkan ada perbedaan yang signifikan antara kecerdasan emosi guru pria dengan kecerdasan emosi guru perempuan. Namun, penelitian ini juga bertolak belakang dengan penelitian Shadiqi, Anward, \& Erlyani (2013) yang membuktikan bahwa tidak ada perbedaan yang signifikan antara mean skor kecerdasan emosional laki-laki dengan perempuan, juga penelitian Irmawati, Tayeb \& Idris (2016) tidak ada hubungan kecerdasan emosional terhadap prestasi belajar mahasiswa ditinjau dari jenis kelamin.

Temuan penelitian terakhir dalam penelitian ini adalah terdapat perbedaan yang signifikan antara tingkat kecerdasan emosi siswa kelas 7 dan kelas 8, dengan kata lain terdapat perbedaan yang signifikan tingkat kecerdasan emosi siswa dari jenjang kelas. Goleman (2001) menyatakan siswa yang lebih tua dapat sama baiknya atau lebih baik dibandingkan siswa yang lebih muda dalam penguasaan kecakapan emosi baru. Remaja adalah tingkat perkembangan anak yang telah mencapai jenjang menjelang dewasa. Pada jenjang ini, kebutuhan remaja telah cukup kompleks, cakrawala interaksi sosial dan pergaulan remaja lebih cukup luas. Dalam penyesuaian dan terhadap lingkungannya, remaja telah mulai memperhatikan dan mengenal berbagai norma pergaulan yang berbeda dengan norma yang berlaku sebelumnya di dalam keluarganya. Remaja menghadapi berbagai lingkungan, bukan saja bergaul dengan berbagai kelompok umur. Dengan demikian, remaja mulai memahami norma pergaulan dengan kelompok remaja. Kelompok anak-anak, kelompok dewasa, dan kelompok orang tua.

\section{KESIMPULAN}


Berdasarkan hasil penelitian dapat disimpulkan: (1) 25,9\% Siswa SMPN di Kota Malang berada pada tingkat kecerdasan emosi tinggi, 61,3\% siswa berada pada tingkat kecerdasan emosi sedang, 12,8\% siswa berada pada tingkat kecerdasan emosi rendah. Dapat disimpulkan bahwa prosentase paling banyak adalah Siswa SMPN yang berada dalam kategori tingkat kecerdasan emosi sedang $(61,3 \%)$. (2) terdapat perbedaan yang signifikan antara tingkat kecerdasan emosi siswa laki-laki dan perempuan atau terdapat perbedaan yang signifikan tingkat kecerdasan emosi siswa berdasarkan jenis kelamin, (3) terdapat perbedaan yang signifikan tingkat kecerdasan emosi siswa dari jenjang kelas. Saran dari penelitian ini bagi pihak sekolah mengingat tingkat kecerdasan emosi siswa masih berada dalam kategori sedang, maka perlu dicanangkan program atau pelatihan untuk dapat meningkatkan kecerdasan emosi siswa menjadi lebih tinggi. Pendidikan dapat menjadi salah satu sarana belajar individu untuk mengembangkan kecerdasan emosi. Siswa mulai dikenalkan dengan berbagai bentuk emosi dan bagaimana mengelolanyanya.

\section{DAFTAR RUJUKAN}

Al Ahyadi, A. (2015). Emotional Spiritual Quotient (ESQ) menurut Ary Ginanjar Agustian dan relevansinya dengan pengembangan kompetensi spiritual dan kompetensi sosial kurikulum 2013 (Doctoral dissertation, UIN Walisongo).

Al Kahtani, A. (2013). Employee emotional intelligence and employee performance in the higher education institutions in Saudi Arabia: A Proposed theoretical framework. International Journal of Business and Social Science, 4(9).

Batool, B. F. (2013). Emotional intelligence and effective leadership. Journal of business studies quarterly, 4(3), 84.

Batubara, J. R. (2016). Adolescent development (perkembangan remaja). Sari pediatri, 12(1), 21-9.

Chong, O. S., Mahamod, Z., \& Yamat, H. (2016). Faktor jantina, kaum, aliran kelas dan hubungannya dengan kecerdasan emosi murid dalam mempelajari Bahasa Melayu. Jurnal Pendidikan Bahasa Melayu, 3(1), $12-23$.

Chow, C. M., Ruhl, H., \& Buhrmester, D. (2013). The mediating role of interpersonal competence between adolescents' empathy and friendship quality: A dyadic approach. Journal of adolescence, 36(1), 191200.

Fitri, N. F., \& Adelya, B. (2017). Kematangan emosi remaja dalam pengentasan masalah. JPGI (Jurnal Penelitian Guru Indonesia), 2(2), 30-39.

Fitriastuti, T. (2013). Pengaruh Kecerdasan Emosional, Komitmen Organisasional dan Organizational Citizenship Behavior terhadap Kinerja Karyawan. Jurnal Dinamika Manajemen, 4(2).

Goleman, D. (2001). Emotional intelligence: Issues in paradigm building. The emotionally intelligent workplace, 13, 26.

Gusniwati, M. (2015). Pengaruh Kecerdasan Emosional Dan Minat Belajar Terhadap Penguasaan Konsep Matematika Siswa Sman Di Kecamatan Kebon Jeruk. Formatif: Jurnal Ilmiah Pendidikan MIPA, 5(1).

Hasanuddin, H. (2018). Perbedaan Kecerdasan Emosi Guru Ditinjau Dari Jenis Kelamin. JURNAL DIVERSITA, 4(1), 26-31.

Hendri, E. (2010). Guru berkualitas: profesional dan cerdas emosi. Jurnal saung guru, 1(2), 1.

Irmawati, I., Tayeb, T., \& Idris, R. (2016). Hubungan Kecerdasan Emosional Terhadap Prestasi Belajar Mahasiswa Ditinjau Dari Jenis Kelamin Pada Jurusan Pendidikan Matematika Uin Alauddin Makassar. MaPan: Jurnal Matematika dan Pembelajaran, 4(2), 156-170.

Jati, G. W., \& Yoenanto, N. H. (2013). Kecerdasan Emosional Siswa Sekolah Menengah Pertama Ditinjau dari Faktor Demografi. Jurnal Psikologi Pendidikan dan Perkembangan, 2(2), 109-123.

Matthews, D. J., \& Folsom, C. (2013). Making connections: cognition, emotion and a shifting paradigm. In The Routledge international companion to gifted education (pp. 42-49). Routledge.

Meyers-Levy, J., \& Loken, B. (2015). Revisiting gender differences: What we know and what lies ahead. Journal of Consumer Psychology, 25(1), 129-149.

Putri, M. P., Asrori, M., \& Astuti, I. (2015). Korelasi Kecerdasan Emosional Dengan Interaksi Sosial Siswa Kelas VII MTs Negeri 2 Pontianak. Jurnal Pendidikan dan Pembelajaran, 4(9).

Rahman, S., Ishak, N. M., MAHMUD, Z., \& Amir, R. (2008). Indeks dan profil kecerdasan emosi pelajar sekolah menengah. Sains Humanika, 48(1).

Setyawan, A. A., \& Simbolon, D. (2018). Pengaruh Kecerdasan Emosional Terhadap Hasil Belajar Matematika Siswa Smk Kansai Pekanbaru. JPPM (Jurnal Penelitian dan Pembelajaran Matematika), 11(1).

Setyawan, I., Budiyono, \& Slamet, I. (2017, August). The comparison of Missouri mathematics project and teams games tournament viewed from emotional quotient eight grade student of junior school. In AIP Conference Proceedings (Vol. 1868, No. 1, p. 050013). AIP Publishing.

Shadiqi, M. A., Anward, H. H., \& Erlyani, N. (2013). Hubungan Antara Kecerdasan Emosional dengan Perilaku Pro-Lingkungan Serta Perbedaannya berdasarkan Jenis Kelamin. Ecopsy, 1(1). 
Uljarevic, M., \& Hamilton, A. (2013). Recognition of emotions in autism: a formal meta-analysis. Journal of autism and developmental disorders, 43(7), 1517-1526.

Yantiek, E. (2014). Kecerdasan Emosi, Kecerdasan Spiritual dan Perilaku Prososial Remaja. Persona: Jurnal Psikologi Indonesia, 3(01).

Yuniarto, P. R. (2016). Masalah globalisasi di Indonesia: Antara kepentingan, kebijakan, dan tantangan. Jurnal Kajian Wilayah, 5(1), 67-95.

Zhang, L. F. (2015). Fostering successful intellectual styles for creativity. Asia Pacific Education Review, 16(2), 183-192. 